\title{
High plasma aldosterone concentration is a novel risk factor of cognitive impairment in patients with hypertension
}

\begin{abstract}
Shusuke Yagi ${ }^{1}$, Masashi Akaike ${ }^{1}$, Ken-ichi Aihara ${ }^{2}$, Takashi Iwase ${ }^{1}$, Sumiko Yoshida ${ }^{2}$, Yuka Sumitomo-Ueda ${ }^{2}$, Yasumasa Ikeda ${ }^{3}$, Kazue Ishikawa ${ }^{1}$, Toshio Matsumoto ${ }^{2}$ and Masataka Sata ${ }^{1}$

Cognitive impairment leading to dementia is associated with high prevalence of hypertension, decreased quality of life and poor prognosis. Aldosterone is known as a risk factor for cardiovascular and cerebrovascular diseases. In addition, mineral corticoid receptors are abundantly expressed in the hippocampus, which plays a pivotal role in cognitive function; however, it has not been determined whether plasma aldosterone level is associated with cognitive impairment in patients with hypertension. We enrolled 68 patients with essential hypertension and assessed their cardiovascular risk factors, including blood pressure, hyperlipidemia, diabetes mellitus, obesity, smoking, history of cerebral infarction, renal function, parameters of inflammation, oxidative stress and nitric oxide bioavailability, a parameter of cerebral blood flow and carotid plaque by ultrasound examination, plasma renin activity and plasma aldosterone concentration (PAC). The mini-mental state examination (MMSE) was used to evaluate cognitive function. The relevance of cardiovascular risk factors and MMSE score was statistically evaluated. Multiple regression analysis showed that age $(P<0.01)$, PAC $(P<0.01)$ and history of cerebral infarction $(P<0.05)$ were inversely and independently associated with MMSE score. Mineral corticoid receptor antagonists, including spironolactone and eplerenone, increased MMSE score in seven patients with hypertension, but not in the controls. In conclusion, increased PAC is associated with impaired cognitive function and mineral corticoid receptor blockade may protect against not only cardiovascular mortality, but also cognitive impairment in patients with hypertension.
\end{abstract}

Hypertension Research (2011) 34, 74-78; doi:10.1038/hr.2010.179; published online 23 September 2010

Keywords: cognitive function; hippocampus; mineral corticoid receptor

\section{INTRODUCTION}

Cognitive impairment (CI) leading to dementia is associated with high prevalence of hypertension, decreased quality of life and poor prognosis. $^{1,2}$ Therefore, prevention of CI is important for promoting public health. As aldosterone causes cardiovascular remodeling in a blood pressure-dependent and -independent manner, ${ }^{3,4}$ it is well known that increased plasma aldosterone level is a risk factor for the development of cardiovascular diseases. ${ }^{5-7}$ In addition, a number of previous studies have shown that blockade of mineral corticoid receptors (MRs) can prevent cerebrovascular events, ${ }^{8,9}$ and MRs are abundantly expressed in the brain, especially in the hippocampus, ${ }^{10}$ which plays a pivotal role in cognitive function. Therefore, there is a possibility that blockade of MRs leads to improvement of cognitive function; ${ }^{11}$ however, it has not been determined whether plasma aldosterone concentration (PAC) is associated with $\mathrm{CI}$ in patients with hypertension. Recently, we experienced a representative case with therapy-resistant essential hypertension manifesting high PAC and CI. Brain magnetic resonance imaging in that patient showed multiple small spotty high-intensity areas in the hippocampus, indicating hippocampal microvascular circulation insufficiency (Figure 1). We therefore hypothesized that increased PAC is associated with severity of CI and that blockade of MRs ameliorates cognitive function in patients with hypertension.

\section{METHODS}

\section{Subjects}

We enrolled 68 patients aged 20-85 years (mean age, $63.3 \pm 14.6$ years) with essential hypertension from outpatients and hospitalized patients of the Department of Cardiovascular Medicine in Tokushima University Hospital. Patient profiles are shown in Table 1. All subjects underwent a standardized interview and physical examination. Hypertensive patients were defined as those with systolic blood pressure $>140 \mathrm{~mm} \mathrm{Hg}$ and/or diastolic blood

${ }^{1}$ Department of Cardiovascular Medicine, The University of Tokushima Graduate School of Health Biosciences, Tokushima, Japan; ${ }^{2}$ Department of Medicine and Bioregulatory Sciences, The University of Tokushima Graduate School of Health Biosciences, Tokushima, Japan and ${ }^{3}$ Department of Pharmacology, The University of Tokushima Graduate School of Health Biosciences, Tokushima, Japan

Correspondence: Dr S Yagi, Department of Cardiovascular Medicine, The University of Tokushima Graduate School of Health Biosciences, 3-18-15 Kuramoto-cho, Tokushima 770-8503, Japan.

E-mail: syagi@clin.med.tokushima-u.ac.jp

Received 19 April 2010; revised 3 June 2010; accepted 15 July 2010; published online 23 September 2010 

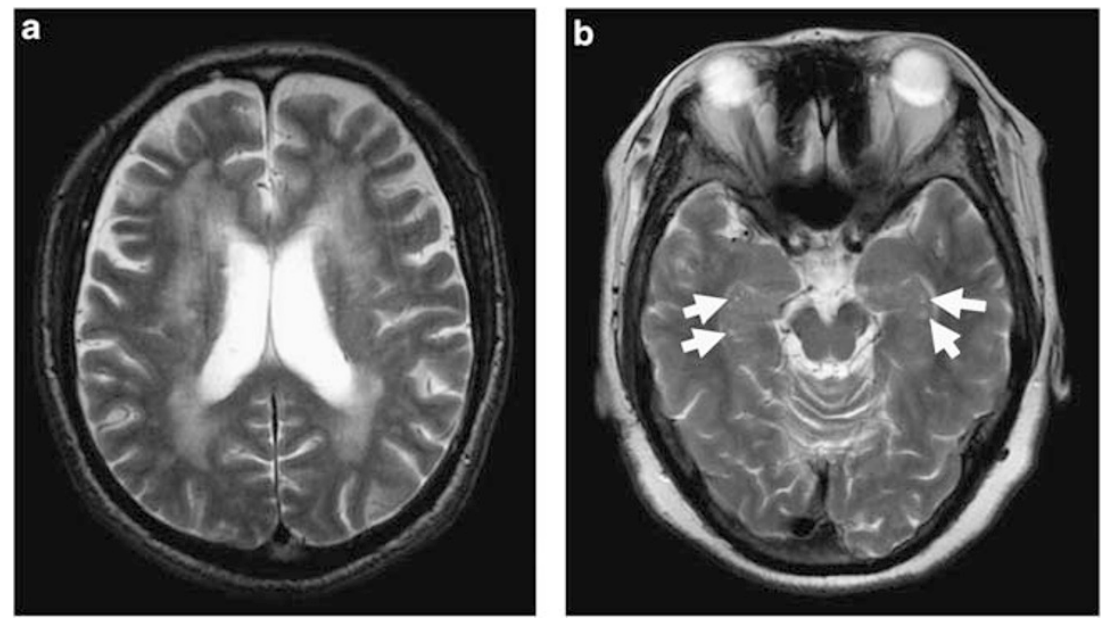

Figure 1 T2-weighted brain magnetic resonance imaging in a patient with high plasma aldosterone concentration. (a) White matter lesion. (b) Multiple spotty high-intensity area in the hippocampus (arrow).

\section{Table 1 Clinical characteristics of subjects}

\begin{tabular}{|c|c|}
\hline Variables & Total $(n=68)$ \\
\hline Age (years) & $63.3 \pm 14.6$ \\
\hline Male, $n(\%)$ & $27(39.7)$ \\
\hline MMSE score & $26.6 \pm 3.9$ \\
\hline Hyperlipidemia, $n(\%)$ & $33(48.5)$ \\
\hline Diabetes mellitus, $n(\%)$ & $23(33.8)$ \\
\hline Atrial fibrillation, $n(\%)$ & $5(7.4)$ \\
\hline Coronary artery disease, $n(\%)$ & $17(25.0)$ \\
\hline Cerebral infarction, $n(\%)$ & $8(11.8)$ \\
\hline Current smoking, $n(\%)$ & $7(10.3)$ \\
\hline Body mass index $\left(\mathrm{kg} \mathrm{m}^{-2}\right)$ & $24.1 \pm 3.31$ \\
\hline Systolic blood pressure $(\mathrm{mm} \mathrm{Hg})$ & $140.9 \pm 22.7$ \\
\hline Diastolic blood pressure $(\mathrm{mm} \mathrm{Hg})$ & $82.1 \pm 14.6$ \\
\hline Mean blood pressure $(\mathrm{mm} \mathrm{Hg})$ & $101.7 \pm 16.4$ \\
\hline Pulse pressure $(\mathrm{mm} \mathrm{Hg})$ & $58.7 \pm 14.1$ \\
\hline Heart rate (b.p.m.) & $67.9 \pm 7.85$ \\
\hline PAC $\left(p g \mathrm{ml}^{-1}\right)$ & $138.6 \pm 54.3$ \\
\hline PRA $\left(\mathrm{ng} \mathrm{m}^{-1} \mathrm{~h}^{-1}\right)$ & $1.75 \pm 2.93$ \\
\hline LDL cholesterol (mg per $100 \mathrm{ml}$ ) & $131.3 \pm 30.3$ \\
\hline HDL cholesterol (mg per $100 \mathrm{ml}$ ) & $56.8 \pm 14.5$ \\
\hline Triglyceride (mg per $100 \mathrm{ml}$ ) & $151.7 \pm 60.7$ \\
\hline Hemoglobin Alc (\%) & $5.9 \pm 0.9$ \\
\hline eGFR $\left(\mathrm{ml} \mathrm{min}-1\right.$ per $\left.1.73 \mathrm{~m}^{2}\right)$ & $64.9 \pm 33.9$ \\
\hline Urinary albumin excretion ( $\mathrm{mgg}^{-1}$ creatinine) & $47.4 \pm 75.8$ \\
\hline B-type natriuretic peptide $\left(\mathrm{pg} \mathrm{ml}^{-1}\right)$ & $83.4 \pm 91.4$ \\
\hline hs-CRP ( $\mu \mathrm{g}$ per $100 \mathrm{ml}$ ) & $135.6 \pm 21.5$ \\
\hline Urinary excretion of $\mathrm{NO}_{x}$ (nmol g ${ }^{-1}$ creatinine) & $27.9 \pm \pm 30.3$ \\
\hline Urinary excretion of $8-\mathrm{OHdG}\left(\mu \mathrm{gg}^{-1}\right)$ creatinine & $6.8 \pm 4.3$ \\
\hline Maximum plaque thickness $(\mathrm{mm})$ & $1.56 \pm 0.65$ \\
\hline Mean CCA blood flow volume $\left(\mathrm{ml} \mathrm{min}{ }^{-1}\right)$ & $342.1 \pm 67.1$ \\
\hline
\end{tabular}

Abbreviations: CCA, common carotid artery; eGFR, estimated glomerular filtration rate; HDL, high-density lipoprotein; hs-CRP, high-sensitivity C-reactive protein; LDL, low-density lipoprotein; MMSE, mini-mental state examination; $\mathrm{NO}_{x}$, nitrate and nitrite; 8-OHdG, 8 -hydroxy-2'-deoxyguanosine; PAC, plasma aldosterone concentration; PRA, plasma renin activity.

pressure $>90 \mathrm{~mm} \mathrm{Hg}$ and individuals on antihypertensive medications. Blood pressure was measured twice in the sitting position and averaged. Mean blood pressure was calculated by $1 / 3$ (systolic blood pressure-diastolic blood pressure)+diastolic blood pressure. Patients with a diagnosis of white-coat hypertension were not categorized as hypertensive. Hyperlipidemic patients were defined as those with low-density lipoprotein cholesterol (LDL-chol) $>140 \mathrm{mg}$ per $100 \mathrm{ml}$ and/or triglyceride levels $>150 \mathrm{mg}$ per $100 \mathrm{ml}$ and individuals on lipid-lowering medications. Diabetics were patients who received insulin and/or oral hypoglycemic agents or individuals with glycosylated hemoglobin Alc $>6.5 \%$. Current smokers were defined as subjects who had smoked within 1 year. Body mass index was calculated as an index of obesity. The exclusion criteria were secondary hypertension, including primary aldosteronism, pheochromocytoma and Cushing's syndrome, symptomatic heart failure, administration of MR blockers, apparent renal disease (serum creatinine $>2.0 \mathrm{mg}$ per $100 \mathrm{ml}$, urinary albumin excretion $>500 \mathrm{mgg}^{-1}$ creatinine). Prior informed consent was obtained from all subjects before enrollment in this study in accordance with protocols approved by the Tokushima University Hospital Ethics Committee.

\section{Mini-mental state examination}

After enrollment, cognitive function was evaluated by mini-mental state examination (MMSE), which is widely used as a screening tool for the assessment of cognitive function. ${ }^{12}$

\section{Ultrasound measurements of carotid artery}

Ultrasound examinations of carotid artery were performed after 15-min rest in the supine position using a Hitachi EUB-8500 ultrasound instrument with a 12-MHz B-mode transducer (Hitachi Medical Corp., Tokyo, Japan). The thickest part of the plaque was recorded as the maximum plaque thickness, and blood flow volume in the common carotid artery, a parameter of cerebral blood flow, was assessed as described previously. ${ }^{13,14}$

\section{MR blocker treatment}

Seven of the patients (mean age, $68.7 \pm 13.8$ years; male/female, $4 / 3$; mean PAC, $199.7 \pm 47.2 \mathrm{pg} \mathrm{ml}^{-1}$ ) were treated with MR blockers (spironolactone in two patients, mean dose, $37.5 \pm 17.7 \mathrm{mg}$; eplerenone in five patients, mean dose, $50.0 \pm 0.0 \mathrm{mg}$ ) in addition to the ongoing treatment for hypertension. MMSE was performed before and 6 months after the administration of MR blockers. Seven age-, sex- and MMSE score-matched patients with essential hypertension were the controls (mean age, $68.0 \pm 8.5$ years; male/female, 4/3; mean PAC, $\left.166.7 \pm 47.6 \mathrm{pg} \mathrm{ml}^{-1}\right)$.

\section{Biochemical analyses}

Before noon, overnight fasting blood and urinary samples were collected for the assessment of cardiovascular risk factors. LDL-chol, triglyceride and highdensity lipoprotein (HDL-chol) were assayed by enzymatic methods. Hemoglobin Alc was assayed by high-performance liquid chromatography. Estimated 
glomerular filtration rate was calculated using the four-variable MDRD (modification of diet in renal disease) formula. Spot urine samples were collected and creatinine and urinary albumin were analyzed; the urinary albumin excretion to urinary creatinine ratio was calculated and expressed as $\mathrm{mg} \mathrm{g}^{-1}$ creatinine. Urinary excretion levels of nitrate and nitrite $\left(\mathrm{NO}_{x}\right)$ as a parameter of the nitric oxide bioavailability were measured by the Griess method (Griess reagent kit for nitrite determination; Invitrogen, Tokyo, Japan) and expressed in $\mathrm{nmolg}^{-1}$ creatinine, and urinary excretion of 8-hydroxy-2'deoxyguanosine as a parameter of oxidative stress was also determined by enzyme-linked immunosorbent assay (new 8-hydroxy-2'-deoxyguanosine Check ELISA Kit; Japan Institute for the Control of Aging, Nikken SEIL Corporation, Shizuoka, Japan) and expressed as $\mu \mathrm{gg}^{-1}$ creatinine. Highsensitivity C-reactive protein levels were measured at Bio Medical Laboratories (Tokyo, Japan) by nephelometry, a latex particle-enhanced immunoassay $(\mathrm{N}$ Latex CRP II). Fasting blood samples for the determination of plasma renin activity (PRA) and PAC were drawn after at least 15-min rest in the sitting position before noon. Angiotensin-converting enzyme inhibitors and angiotensin receptor blockers, which are capable of affecting PRA and PAC, were replaced with calcium channel blockers or $\alpha$-blockers at least 2 weeks before blood sampling. PRA was measured with a radioimmunoassay (Renin RIA kit, Yamasa Soysause, Chiba, Japan). PAC was measured with a radioimmunoassay at a commercially available laboratory (SRL, Tokyo, Japan). The intra- and inter-assay coefficients of variation were 4.8 and $4.6 \%$, respectively.

\section{Statistical analysis}

Continuous variables were averaged; each value is expressed as the mean \pm s.d. or as a percentage for categorical parameters. Gender and presence of hyperlipidemia, diabetes mellitus, current smoking and history of cerebral infarction were coded as dummy variables. Single regression analysis was used to assess the correlations between MMSE score (natural log-transformed) and cardiovascular risk factors. The degree of association among independent variables, including age, PAC, LDL-chol, hemoglobin Alc and history of cerebral infarction was assessed by multiple regression analyses (stepwise regression model). MMSE score and blood pressure-related parameters were compared before and after treatment with MR blockers by the paired $t$-test. All statistical analyses were performed using SPSS software. Statistical significance was defined as $P<0.05$.

\section{RESULTS}

Case

A representative case, a 54-year-old female patient with therapy-resistant essential hypertension manifesting high PAC and CI: PAC of $177 \mathrm{pg} \mathrm{ml}^{-1}$ and MMSE score of 24. T2-weighted brain magnetic resonance imaging in that patient showed multiple spotty high-intensity areas in the hippocampus as well as in the cerebral white matter, indicating hippocampal microvascular circulation insufficiency (Figure 1). The patient was treated with a mineral corticoid antagonist (eplerenone, $50 \mathrm{mg}$ ) in addition to a calcium channel blocker (amlodipine, $5 \mathrm{mg}$ ) for 6 months, and MMSE score increased from 24 to 27 along with decrease in blood pressure from $160 / 94$ to $138 / 84 \mathrm{~mm} \mathrm{Hg}$

\section{Distribution of MMSE scores}

MMSE scores of the subjects enrolled in this study are shown in Table 1. The mean MMSE score was $26.6 \pm 3.9$ and it ranged from 14 to 30 . Nine patients $(13.2 \%)$ were defined as having CI owing to low MMSE score below 24 (Figure 2a).

\section{Correlation between PAC and MMSE score}

Single regression analysis showed that age, PAC, LDL-chol, hemoglobin A1c and history of cerebral infarction were inversely associated with MMSE score (Table 2 and Figure 2b). There were no relationships of CI with gender, systolic, diastolic and mean blood pressure, pulse pressure, PRA, HDL-chol, triglyceride, body mass index, estimated glomerular filtration rate, urinary albumin excretion, maximum
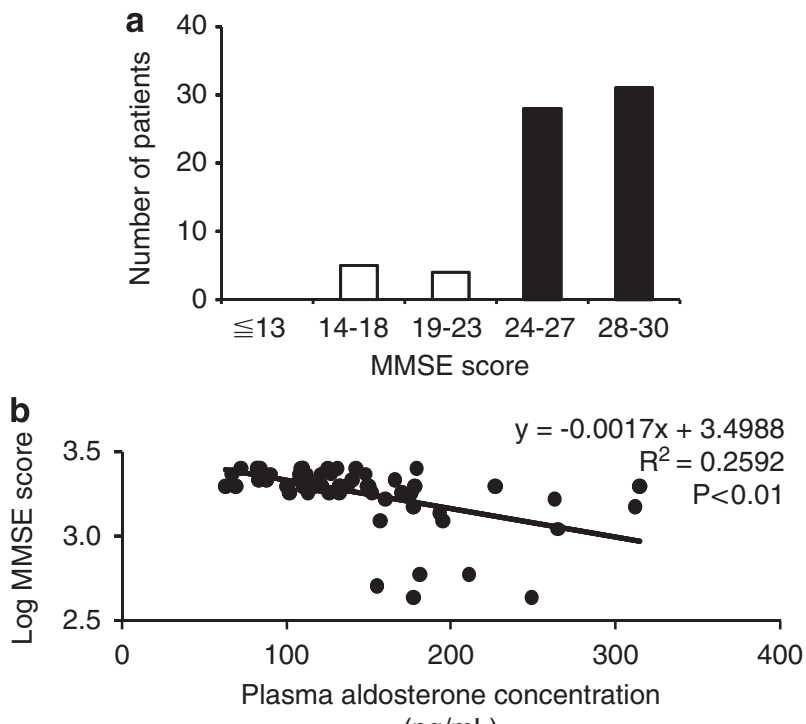

$(\mathrm{pg} / \mathrm{mL})$

Figure 2 (a) Distribution of mini-mental state examination (MMSE) scores. White bar: MMSE < 24 indicating cognitive impairment; black bar: MMSE $\geqq 24$. (b) Association between MMSE score and plasma aldosterone concentration.

Table 2 Simple linear regression analysis for determinants of MMSE score

\begin{tabular}{lrr}
\hline Variables & Coefficient & P-value \\
\hline Age & -0.50 & $<0.01$ \\
Male & -0.14 & 0.26 \\
Systolic blood pressure & -0.02 & 0.84 \\
Diastolic blood pressure & -0.02 & 0.85 \\
Mean blood pressure & -0.03 & 0.80 \\
Pulse pressure & -0.04 & 0.76 \\
PAC & -0.51 & $<0.01$ \\
PRA & 0.22 & 0.09 \\
LDL cholesterol & -0.25 & $<0.05$ \\
HDL cholesterol & 0.11 & 0.38 \\
Triglyceride & 0.07 & 0.56 \\
Hemoglobin Alc & -0.39 & $<0.01$ \\
Body mass index & 0.01 & 0.94 \\
eGFR & $<0.01$ & 0.99 \\
Urinary albumin excretion & -0.08 & 0.52 \\
Maximum plaque thickness & -0.01 & 0.92 \\
Mean CCA blood flow volume & 0.23 & 0.07 \\
hs-CRP & -0.02 & 0.89 \\
Urinary excretion of NO ${ }_{x}$ & 0.16 & 0.19 \\
Urinary excretion of 8-OHdG & -0.12 & 0.34 \\
Cerebral infarction & -0.32 & $<0.01$ \\
Hyperlipidemia & 0.03 & 0.82 \\
Diabetes mellitus & 0.09 & 0.45 \\
Current smoking & -0.17 & 0.17 \\
\hline Abrention & &
\end{tabular}

Abbreviations: CCA, common carotid artery; eGFR, estimated glomerular filtration rate; $\mathrm{HDL}$, high-density lipoprotein; hs-CRP, high-sensitivity C-reactive protein; LDL, low-density lipoprotein; MMSE, mini-mental state examination; $\mathrm{NO}_{x}$, nitrate and nitrite; 8-OHdG, 8-hydroxy-2'-deoxyguanosine; PAC, plasma aldosterone concentration; PRA, plasma renin activity.

plaque thickness, blood flow volume in the common carotid artery, high-sensitivity C-reactive protein, urinary excretion of $\mathrm{NO}_{x}$, urinary excretion of 8-hydroxy-2'-deoxyguanosine, hyperlipidemia, diabetes mellitus and current smoking. 
Table 3 Multiple regression analysis for determinants of MMSE score

\begin{tabular}{lcccc}
\hline Variables & Coefficient & $\begin{array}{c}95 \% \text { Confidence } \\
\text { interval }\end{array}$ & $\begin{array}{c}\text { Standardized } \\
\text { coefficient }\end{array}$ & P-value \\
\hline Age & -0.12 & -0.07 to -0.17 & -0.43 & $<0.01$ \\
PAC & -0.03 & -0.02 to -0.04 & -0.41 & $<0.01$ \\
Cerebral infarction & -2.6 & -0.57 to -4.63 & -0.22 & $<0.05$ \\
\hline
\end{tabular}

Abbreviations: MMSE, mini-mental state examination; PAC, plasma aldosterone concentration. $R^{2}=0.52, P<0.01$

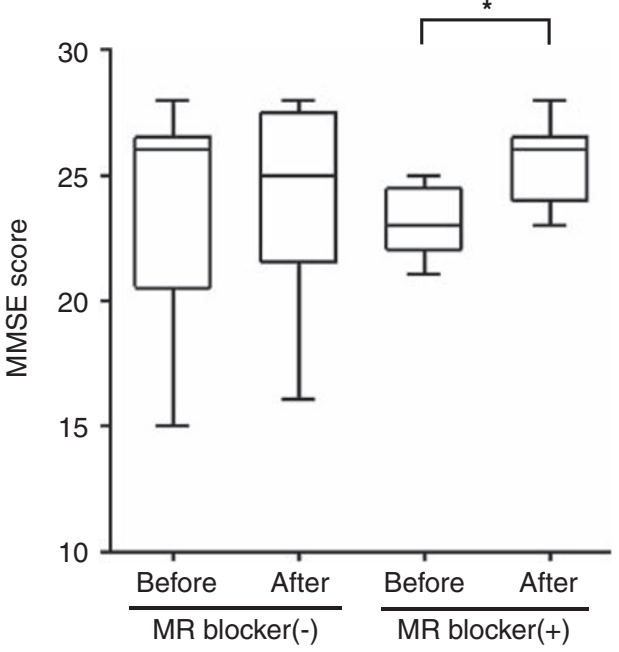

Figure 3 Comparison of mini-mental state examination (MMSE) score with/ without MR (mineral corticoid receptor) blocker treatment. ${ }^{*} P<0.05$

Multiple regression analysis was performed to elucidate independent determinants of MMSE score, and it was shown that age $(P<0.01)$, PAC $(P<0.01)$ and history of cerebral infarction $(P<0.05)$ were independent negative contributors to MMSE score; however, LDL-chol and hemoglobin Alc were statistically excluded (Table 3).

\section{Increase in MMSE score by MR blockers}

In addition to decrease in blood pressure (systolic blood pressure: $150.6 \pm 19.2$ before and $136.9 \pm 8.1 \mathrm{~mm} \mathrm{Hg}$ after, $P<0.05$; diastolic blood pressure: $90.6 \pm 13.2$ before and $75.7 \pm 10.9 \mathrm{~mm} \mathrm{Hg}$ after, NS; mean blood pressure: $110.6 \pm 14.8$ before and $96.1 \pm 9.2 \mathrm{~mm} \mathrm{Hg}$ after, NS), MMSE score in patients who received 6-month treatment with MR blockers showed significant amelioration (MMSE score: $23.7 \pm 2.7$ before and $25.4 \pm 1.9$ after, $P<0.05$; Figure 3 ). The controls exhibited no changes in blood pressure and MMSE score during the study period (systolic blood pressure: 152.5 \pm 23.8 before and $142.3 \pm$ $14.6 \mathrm{~mm} \mathrm{Hg}$ after, NS; diastolic blood pressure: $88.6 \pm 16.9$ before and $87.1 \pm 8.9 \mathrm{~mm} \mathrm{Hg}$ after, NS; mean blood pressure: $109.9 \pm 18.8$ before and $105.5 \pm 10.6 \mathrm{~mm} \mathrm{Hg}$ after, NS; MMSE score: $23.3 \pm 5.4$ before and $23.8 \pm 4.7$ after, NS; Figure 3 ).

\section{DISCUSSION}

We showed that high PAC is a novel potent and independent risk factor for impaired cognitive function in addition to the conventional risk factors, including age and history of cerebral infarction.

$\mathrm{CI}$ and its end point dementia are characterized by progressive memory loss, disorientation in time and space, loss of autonomy and, ultimately, depersonalization/alienation. Dementia consists of degenerative dementia, including Alzheimer disease and vascular dementia, due to cerebral deposition of $\beta$-amyloid and cerebral vascular circulation insufficiency, respectively. ${ }^{15}$ The mechanisms of dementia have been investigated; however, methods for treating dementia have not been fully established. Therefore, early detection of CI is needed for early treatment and prevention of dementia.

Hypertension is associated with increased risk for CI leading to vascular dementia and Alzheimer disease, suggesting that blood pressure lowering reduces the incidence of dementia. ${ }^{16-21}$ In addition, as angiotensin-converting enzyme inhibitors, angiotensin receptor blockers and potassium sparing diuretics have an advantage in preventing CI, activation of the renin-angiotensin system or low potassium concentration has been suggested to be involved in CI through possible contributors to CI pathogenesis, including oxidative stress, inflammation, platelet aggregation and vasoconstriction. ${ }^{22-29}$

Aldosterone, a crucial factor downstream of the renin-angiotensinaldosterone system, has also been shown to cause target organ damage independent of its effects on blood pressure and to be a potent cerebrovascular risk factor. In this study, we showed that increased PAC is associated with CI. It has been reported that hippocampal hypoperfusion evaluated by single photon emission computed tomography or hippocampal sclerosis evaluated by magnetic resonance imaging were associated with $\mathrm{CI},{ }^{30,31}$ and that blockade of the reninangiotensin-aldosterone system increases hippocampal blood flow, ${ }^{32}$ indicating that aldosterone-induced microvessel circulation insufficiency in the hippocampus causes CI. As aldosterone can reach brain tissue through the blood-brain barrier, the level of aldosterone in the brain is directly proportional to that in the plasma even though aldosterone is synthesized in the brain. ${ }^{33-35}$ In addition, MRs have been identified not only in blood vessels, but also in the brain, especially in the hippocampus, which serves a critical role in cognitive function. ${ }^{36-38}$ These findings may support our speculation that aldosterone-induced cerebrovascular remodeling and cerebral damage in the hippocampus are involved in hippocampal dysfunction leading to CI. Further examinations, including evaluation of ACE activity and angiotensin II concentration in addition to PRA and PAC, are needed to isolate the influence of aldosterone on CI from a secondary effect of activation of the renin-angiotensin-aldosterone system.

In this study, we showed that MR blockers ameliorated cognitive function in patients with essential hypertension, indicating that MR blocker therapy in hypertensive patients with increased PAC is an efficient therapeutic strategy for preventing CI; however, the results of this preliminary study with a small number of patients did not show a blood pressure-lowering-independent effect of MR blockers against CI. Comparisons of MR blockers with other blood pressure-lowering agents by large clinical cohort studies are needed to clarify the favorable effects of MR blockade.

In conclusion, high PAC is associated with impaired cognitive function and MR blockade may have a protect effect against not only cardiovascular mortality, but also CI in patients with hypertension.

\section{CONFLICT OF INTEREST}

The authors declare no conflict of interest.

\section{ACKNOWLEDGEMENTS}

This work was supported in part by Grants-in-Aid for Scientific Research from the Ministry of Education, Science, Sports and Culture of Japan and by Grant for a Study Group on Aseptic Femoral Neck Necrosis from the Ministry of Health, Labour and Welfare of Japan. 
1 Qiu C, Winblad B, Fratiglioni L. The age-dependent relation of blood pressure to cognitive function and dementia. Lancet Neurol 2005; 4: 487-499.

2 Hoshide S, Ishikawa J, Eguchi K, Oowada T, Shimada K, Kario K. Cognitive dysfunction and physical disability are associated with mortality in extremely elderly patients. Hypertens Res 2008; 31: 1331-1338.

3 Weber KT, Janicki JS, Pick R, Capasso J, Anversa P. Myocardial fibrosis and pathologic hypertrophy in the rat with renovascular hypertension. Am J Cardiol 1990; 65: 1G-7G.

4 Stier Jr CT, Chander PN, Rocha R. Aldosterone as a mediator in cardiovascular injury. Cardiol Rev 2002; 10: 97-107.

5 Conn JW, Knopf RF, Nesbit RM. Clinical characteristics of primary aldosteronism from an analysis of 145 cases. Am J Surg 1964; 107: 159-172.

6 Litchfield WR, Anderson BF, Weiss RJ, Lifton RP, Dluhy RG. Intracranial aneurysm and hemorrhagic stroke in glucocorticoid-remediable aldosteronism. Hypertension 1998; 31: 445-450.

7 Stier Jr CT, Rocha R, Chander PN. Effect of aldosterone and MR blockade on the brain and the kidney. Heart Fail Rev 2005; 10: 53-62.

8 Rocha R, Stier Jr CT. Pathophysiological effects of aldosterone in cardiovascular tissues. Trends Endocrinol Metab 2001; 12: 308-314.

9 Dorrance AM, Osborn HL, Grekin R, Webb RC. Spironolactone reduces cerebral infarct size and EGF-receptor mRNA in stroke-prone rats. Am J Physiol Regul Integr Comp Physiol 2001; 281: R944-R950.

10 Reul JM, Gesing A, Droste S, Stec IS, Weber A, Bachmann C, Bilang-Bleuel A, Holsboer $F$, Linthorst AC. The brain mineralocorticoid receptor: greedy for ligand, mysterious in function. Eur J Pharmacol 2000; 405: 235-249.

11 Otte C, Moritz S, Yassouridis A, Koop M, Madrischewski AM, Wiedemann K, Kellner M. Blockade of the mineralocorticoid receptor in healthy men: effects on experimentally induced panic symptoms, stress hormones, and cognition. Neuropsychopharmacology 2007; 32: 232-238.

12 Folstein MF, Folstein SE, McHugh PR. Mini-mental state. A practical method for grading the cognitive state of patients for the clinician. J Psychiatr Res 1975; 12: 189-198.

13 Aihara K, Azuma H, Takamori N, Kanagawa Y, Akaike M, Fujimura M, Yoshida T, Hashizume S, Kato M, Yamaguchi H, Kato S, Ikeda Y, Arase T, Kondo A, Matsumoto T. Heparin cofactor II is a novel protective factor against carotid atherosclerosis in elderly individuals. Circulation 2004; 109: 2761-2765.

$14 \mathrm{Ho}$ SS, Metreweli C. Preferred technique for blood flow volume measurement in cerebrovascular disease. Stroke 2000; 31: 1342-1345.

15 Kitagawa K, Oku N, Kimura Y, Yagita Y, Sakaguchi M, Hatazawa J, Sakoda S. Relationship between cerebral blood flow and later cognitive decline in hypertensive patients with cerebral small vessel disease. Hypertens Res 2009; 32: 816-820.

16 Forette F, Seux ML, Staessen JA, Thijs L, Babarskiene MR, Babeanu S, Bossini A, Fagard R, Gil-Extremera B, Laks T, Kobalava Z, Sarti C, Tuomilehto J, Vanhanen H, Webster J, Yodfat Y, Birkenhager WH. The prevention of dementia with antihypertensive treatment: new evidence from the Systolic Hypertension in Europe (Syst-Eur) study. Arch Intern Med 2002; 162: 2046-2052.

17 Tzourio C, Anderson C, Chapman N, Woodward M, Neal B, MacMahon S, Chalmers J. Effects of blood pressure lowering with perindopril and indapamide therapy on dementia and cognitive decline in patients with cerebrovascular disease. Arch Intern Med 2003; 163: 1069-1075.

18 Lithell H, Hansson L, Skoog I, Elmfeldt D, Hofman A, Olofsson B, Trenkwalder P, Zanchetti A. The Study on COgnition and Prognosis in the Elderly (SCOPE); outcomes in patients not receiving add-on therapy after randomization. J Hypertens 2004; 22: 1605-1612.

19 Rigaud AS, Seux ML, Staessen JA, Birkenhager WH, Forette F. Cerebral complications of hypertension. J Hum Hypertens 2000; 14: 605-616.

20 Birkenhager WH, Forette F, Seux ML, Wang JG, Staessen JA. Blood pressure, cognitive functions, and prevention of dementias in older patients with hypertension. Arch Intern Med 2001; 161: 152-156.
21 Hanon O, Berrou JP, Negre-Pages L, Goch JH, Nadhazi Z, Petrella R, Sedefdjian A, Sevenier F, Shlyakhto EV, Pathak A. Effects of hypertension therapy based on eprosartan on systolic arterial blood pressure and cognitive function: primary results of the observational study on cognitive function and systolic blood pressure reduction open-label study. J Hypertens 2008; 26: 1642-1650.

22 Wang J, Ho L, Chen L, Zhao Z, Zhao W, Qian X, Humala N, Seror I, Bartholomew S, Rosendorff C, Pasinetti GM. Valsartan lowers brain beta-amyloid protein levels and improves spatial learning in a mouse model of Alzheimer disease. J Clin Invest 2007; 117: 3393-3402.

23 Takeda S, Sato N, Takeuchi D, Kurinami H, Shinohara M, Niisato K, Kano M, Ogihara T, Rakugi H, Morishita R. Angiotensin receptor blocker prevented beta-amyloid-induced cognitive impairment associated with recovery of neurovascular coupling. Hypertension 2009; 54: 1345-1352.

24 Mogi M, Horiuchi M. Effects of angiotensin II receptor blockers on dementia. Hypertens Res 2009; 32: 738-740.

25 Ito S, Komatsu K, Yajima Y, Hirayama A. Renin-angiotensin system in the brain as a new target of antihypertensive therapy. Hypertens Res 2008; 31: 1487-1488.

26 Morishita R. Aegis against stroke and dementia by angiotensin type 1 receptor blockers: new beneficial aspects. Hypertens Res 2008; 31: 1-3.

27 Horiuchi M, Mogi M, Iwai M. The angiotensin II type 2 receptor in the brain. J Renin Angiotensin Aldosterone Syst 2010; 11: 1-6.

28 Li NC, Lee A, Whitmer RA, Kivipelto M, Lawler E, Kazis LE, Wolozin B. Use of angiotensin receptor blockers and risk of dementia in a predominantly male population: prospective cohort analysis. BMJ 2010; 340: b5465.

29 Khachaturian AS, Zandi PP, Lyketsos CG, Hayden KM, Skoog I, Norton MC, Tschanz JT, Mayer LS, Welsh-Bohmer KA, Breitner JC. Antihypertensive medication use and incident Alzheimer disease: the Cache County Study. Arch Neurol 2006; 63: 686-692.

30 Ohnishi T, Hoshi H, Nagamachi S, Jinnouchi S, Flores II LG, Futami S, Watanabe K. High-resolution SPECT to assess hippocampal perfusion in neuropsychiatric diseases. J Nucl Med 1995; 36: 1163-1169.

31 Sepe-Monti M, De Carolis A, Bomboi G, Castri P, Giubilei F. MRI evidence of bilateral hippocampal sclerosis in amnestic mild cognitive impairment. Eur J Neurol 2006; 13: 1031-1032.

32 Manschot SM, Biessels GJ, Cameron NE, Cotter MA, Kamal A, Kappelle LJ, Gispen $\mathrm{WH}$. Angiotensin converting enzyme inhibition partially prevents deficits in water maze performance, hippocampal synaptic plasticity and cerebral blood flow in streptozotocindiabetic rats. Brain Res 2003; 966: 274-282.

33 Birmingham MK, Sar M, Stumpf WE. Localization of aldosterone and corticosterone in the central nervous system, assessed by quantitative autoradiography. Neurochem Res 1984; 9: 333-350.

34 Funder J, Myles K. Exclusion of corticosterone from epithelial mineralocorticoid receptors is insufficient for selectivity of aldosterone action: in vivo binding studies. Endocrinology 1996; 137: 5264-5268.

35 Uhr M, Holsboer F, Muller MB. Penetration of endogenous steroid hormones corticosterone, cortisol, aldosterone and progesterone into the brain is enhanced in mice deficient for both mdrla and mdr1b P-glycoproteins. J Neuroendocrinol 2002; 14: 753-759.

36 Yau JL, Olsson T, Morris RG, Meaney MJ, Seckl JR. Glucocorticoids, hippocampal corticosteroid receptor gene expression and antidepressant treatment: relationship with spatial learning in young and aged rats. Neuroscience 1995; 66: 571-581.

37 Roland BL, Krozowski ZS, Funder JW. Glucocorticoid receptor, mineralocorticoid receptors, 11 beta-hydroxysteroid dehydrogenase- 1 and -2 expression in rat brain and kidney: in situ studies. Mol Cell Endocrinol 1995; 111: R1-R7.

38 Takeda Y, Miyamori I, Inaba S, Furukawa K, Hatakeyama H, Yoneda T, Mabuchi H, Takeda R. Vascular aldosterone in genetically hypertensive rats. Hypertension 1997; 29: 45-48. 